\title{
Breast Cancer and PET Imaging
}

Ismet Sarikaya (iD

Kuwait University Faculty of Medicine, Department of Nuclear Medicine, Kuwait City, Kuwait

[Received 16 V 2020; Accepted 21 X 2020]

\begin{abstract}
Breast cancer is the most common malignancy in women and among the most common indications of oncologic positron emission tomography (PET) studies. In this review article, updated anatomical, pathological, and clinical information about breast cancer were provided for Nuclear Medicine physicians to better understand breast cancer and interpret PET images and a review of the literature on the use of PET imaging in breast cancer was summarized.
\end{abstract}

KEY words: Breast cancer; PET, FDG; NaF; FES

Nucl Med Rev 2021; 24, 1: 16-26

\section{Introduction}

Breast cancer is the most common malignancy in women worldwide (2.1 million women each year) [1]. Approximately 627,000 women died from breast cancer in 2018 [1]. Breast cancer rates are higher in western countries but also increasing in the rest of the world. Breast cancer incidence and death rates generally increase with age. Survival is affected by the stage of the disease as well as histological and molecular subtypes and genomic profile of the breast cancer and ranges from $99 \%$ to $27 \%$ [2].

Breast cancer is among the most common oncologic indications of clinical Positron emission tomography/computed tomography (PET/CT) studies. Among various PET radiotracers, ${ }^{18} \mathrm{~F}$-fluorodeoxyglucose (FDG) and ${ }^{18} \mathrm{~F}$-sodium fluoride (NaF) are the main radiotracers used in clinical $P E T$ studies for initial staging of locally advanced invasive and inflammatory breast cancers, to assess response to treatments and to detect and localize the recurrent disease. More specific PET radiotracers, such as ${ }^{18} \mathrm{~F}$-fluoroestradiol (FES/oestrogen receptor binding), ${ }^{18} \mathrm{~F}$-fluorothymidine (FLT/cell proliferation), ${ }^{89} \mathrm{Zr}$-trastuzumab (human epidermal growth factor receptor 2 (HER2) binding) ${ }^{18} \mathrm{~F}$-galacto-RGD (angiogenesis), ${ }^{18} \mathrm{~F}$-annexin-V (apoptosis), ${ }^{89} \mathrm{Zr}$-anti-gH2AX-TAT (cell death), ${ }^{18} \mathrm{~F}$-FMISO (hypoxia) are mainly used for investigational purpose.

This review article aims to provide practically useful information about breast cancer and the role of PET/CT in the management of breast cancer.

\section{Anatomy and Histology of the Breast}

Breasts overly the pectoralis major muscles with a fascia in between them. The mammary gland is an exocrine gland composed

Correspondence to: Ismet Sarikaya

Department of Nuclear Medicine, Faculty of Medicine, Kuwait University, PO Box 24923 Safat, Kuwait 13110

phone: (965) 25319592 / 6414; fax: (965) 25338936

e-mail: isarikaya99@yahoo.com of mammary lobules and network of ducts. Each mammary lobule consists of small glandular structures (acini) which open into the terminal duct (terminal duct lobular unit, TDLU). Ducts and mammary lobules are surrounded by connective tissue which is composed of blood and lymphatic vessels, nerves, adipose and fibrous tissue [3].

Breasts have 2 superficial (cutaneous and subcutaneous) and 2 deep (mammary-glandular and fascial) intercommunicating lymphatic plexi. Superficial lymphatics drain the skin, whereas deep lymphatics drain the breast parenchyma, areola and the nipple. The density of the lymphatic plexus is higher in the subareolar region (Sappey's plexus). In 1874, Sappey suggested that axillary nodes receive lymphatic drainage from the entire breast via the subareolar plexus. However, the role of the subareolar plexus in the lymphatic drainage of the breast is still controversial [4]. Approximately $75 \%$ of breast lymphatic drainage is directed to the axilla and $25 \%$ to the internal mammary nodes [5]. However, internal mammary node drainage was seen in $28-44 \%$ of all patients with breast carcinomas on lymphoscintigraphy studies [6]. There are three levels of lymph nodes in the axilla. Level I nodes are inferolateral to the pectoralis minor, level II nodes are behind the pectoralis minor, and level 3 nodes are superomedial to the pectoralis minor. Axillary lymphatic drainage generally proceeds in a stepwise fashion from level I to level II, to level III and finally into the thoracic duct. When there is an obstruction in the axillary lymphatic flow or after the axillary dissection, alternative pathways may become important for the lymphatic drainage (altered lymphatic drainage) through various lymph nodes such as internal mammary, presternal, retrosternal, transpectoral, retro pectoral, posterior intercostal and subdiaphragmatic (Gerota's route) nodes. The lymph nodes between pectoralis minor and major muscles (interpectoral) are called rotter space nodes.

\section{Diagnosis of Breast Cancer}

For women at average breast cancer risk, American Cancer Society (ACS) recommends yearly screening mammogram for women 45 to 54-year-old [7]. Women 55 year and older can have a mammogram yearly or every other year [7]. For women at high 
breast cancer risk, ACS recommends yearly breast magnetic resonance imaging (MRI) and a mammogram, typically starting at age 30 [7]. High risk includes having a family history of breast cancer, history of radiation therapy to the chest between the ages of 10 and 30 years, and patient or $1^{\text {st }}$ degree relative to have a BRCA 1 or BRCA2 gene mutation, Li-Fraumeni syndrome, Cowden syndrome, or Bannayan-Riley-Ruvalcaba syndrome [7].

Screening mammograms mainly search for calcification and masses and also assess the density of the breast. Macro-calcifications are usually due to benign conditions. Micro-calcifications are more concerning than macro-calcifications. Thirty per cent of patients with breast micro-calcifications showed malignancy on histopathology [8]. Dense breasts are linked to a higher risk of breast cancer. Dense breast tissue can also prevent the detection of cancers on a mammogram. To describe mammogram findings, a standard system is used (Breast Imaging Reporting and Data System (BI-RADS)) [7]. BI-RADS scores range from 0 to 6; 0: Incomplete study, additional imaging and/or comparison to prior mammograms is needed, 1: Negative study, 2: Benign findings, 3: Probably benign findings with follow-up in 6 mos, 4: Suspicious findings, biopsy should be considered, 5: Highly suggestive of malignancy, biopsy should be considered, and 6: Known biopsy-proven malignancy.

Breast ultrasound helps to differentiate simple cysts from solid masses and guide biopsy. Breast MRI has a limited role in the screening of breast cancer, but it should be considered in women who have a high risk of breast cancer. After the diagnosis of breast cancer, MRI is useful to assess the primary tumour (tumour size, multifocal vs multicentre disease) and chest wall invasion.

\section{Classification of Breast Cancers}

Most breast cancers are adenocarcinoma and arise from the epithelial cells of the TDLU. A small number of breast cancers arise in the other tissues such as fat, muscle, and connective tissue. As the glandular tissue is more abundant in the upper outer quadrant of the breast, half of the breast cancers occur in this region [9].

Histological classification of breast cancers includes in-situ carcinoma (cancerous cells remain in the place and have not spread yet) and invasive or infiltrating carcinoma (cancer cells spread beyond the layer of tissue in which they developed).

In situ carcinomas are classified as ductal carcinoma in situ (DCIS or intraductal carcinoma) and Paget's disease. DCIS is a non-invasive, pre-invasive breast cancer where proliferations of malignant ductal epithelial cells remain confined within intact breast ducts. Paget's disease is a rare type of breast cancer involving the skin of the nipple. Paget's disease is usually linked to DCIS or invasive ductal carcinoma (IDC). Lobular carcinoma in-situ is treated as a benign entity and has been removed from TNM staging. It is considered as a proliferative disease with associated risk for developing breast cancer in the future [9].

The invasive breast carcinomas are classified as ductal, inflammatory, medullary, medullary with lymphoid stroma, mucinous, papillary (predominantly micropapillary pattern), tubular, lobular, infiltrating Paget's disease, undifferentiated, squamous cell, adenoid cystic, secretory, and cribriform [10]. If the tumour has no specific differentiating features, it is called invasive carcinoma not otherwise specified (NOS). Invasive mammary cancer has features of both ductal carcinoma and lobular carcinoma. IDC is the most common invasive tumour of the breast which comprises 72-80 $\%$ of all invasive breast cancers [11]. Invasive lobular carcinoma (ILC) accounts for 5-15\% and inflammatory breast cancer accounts for $1 \%$ to $2 \%$ of all invasive breast cancers [2, 11]. IDC is further sub-classified as well-differentiated (grade 1), moderately differentiated (grade 2) or poorly differentiated (grade 3) based on the levels of nuclear pleomorphism, glandular/tubule formation and mitotic index [12]. Inflammatory carcinoma is characterized by diffuse erythema and oedema (peau d'orange) in the skin of the breast with a rapid evolution [9]. Inflammatory carcinoma is a clinical-stage T4d cancer and the most aggressive presentation of breast cancer [13]. An underlying mass may or may not be palpable and there may be a detectable mass on the imaging [9]. Changes in the skin may be due to lymphedema caused by tumour emboli within dermal lymphatics [9,]. ILC of the breast shows low histological grade and low mitotic count [14].

Hormone receptor (oestrogen receptor (ER) and progesterone receptor (PR)) and human epidermal growth factor receptor 2 (HER2) expressions of breast cancer are assessed via qualitative and/or semi-quantitative immunohistochemistry technique on biopsied tissues.

Through molecular analysis and gene expression profiling, breast cancer is sub-classified into luminal $A(E R+/ P R+)$, luminal $\mathrm{B}(\mathrm{ER}+/ \mathrm{PR}+/ \mathrm{HER} 2+$ or - , Ki67+), HER2 enriched (HER2+) and basal-like (triple-negative, ER-/PR-/HER2-).

$\mathrm{ER}+$ tumours comprise up to $75 \%$ of all breast cancer patients. ER + tumours largely well-differentiated and less aggressive [15]. $\mathrm{PR}+$ tumours are mostly ER+ [16]. ER+PR-tumours are less responsive to endocrine treatment than ER+PR+ tumours [16]. HER2 positivity is associated with poor differentiation and aggressive tumour and seen in $13 \%$ to $20 \%$ of IDC [16]. HER2 positivity is very rarely seen in low-grade IDC or traditional ILC. ILC is generally positive for hormone receptor and negative for HER2, p53 and basal marker [14].

$\mathrm{Ki} 67$ is the most widely used proliferation marker in breast cancer which is predominantly present in cycling cells. It is associated with aggressive tumours, worse prognosis and survival.

P53 is a tumour suppressor gene. Mutation in p53 causes loss of control of cell proliferation. p53 is the most frequently mutated gene in invasive breast cancer which is seen in $30-35 \%$ of all cases, and approximately $80 \%$ of triple-negative tumours [17].

Genomic assays or tests analyse the tumour tissue to determine if there are certain genes which can affect the cancer growth, spread and recurrence. Genetic testing should not be mistaken for genomic testing. In genetic testing, blood, saliva or other tissues are analysed to determine if there is abnormal change or mutation in a gene which is linked to high risk of cancer development. There are several genomic assays for breast cancer such as OncotypeDx, Mammaprint, Endopredict, PAM50 (Prosigna) and Breast cancer Index [9]. OncotypeDx is the only multigene panel included to classify pathological prognostic staging of breast cancer. The OncotypeDx test analyses the activity of 21 genes and calculates a recurrence score.

\section{Staging of Breast Cancer}

Traditional staging (TNM, tumour: T, lymph nodes: N, and distant metastases: $M)$ is still used in places where biomarker tests are not available (Tab. 1) [9]. TNM staging is classified as Clinical "c" and 
Table 1. Summary of AJCC TNM staging (clinical T, pathological N)

$\begin{array}{ll}\text { Tis } & \text { DCIS or Paget } \\ \text { T1 } & \text { Tm size } \leq 20 \\ \text { T2 } & \text { Tm size }>20 \mathrm{~mm}, \leq 50 \mathrm{~mm} \\ \text { T3 } & \text { Tm size }>50 \mathrm{~mm} \\ \text { T4 } & \text { T4a Extension to chest wall* } \\ & \text { T4b Ulceration or macroscopic nodules in the skin } \\ & \text { T4c T4a }+ \text { T4b } \\ & \text { T4d Inflammatory carcinoma }\end{array}$

*Chest wall: Ribs, intercostal muscles and serratus anterior muscle.

Adherence/invasion to the pectoralis muscle is NOT extension to the chest wall

$\begin{array}{ll}\text { No } & \text { No regional lymph node metastasis or } \leq 0.2 \mathrm{~mm} \\ \text { N1 } & \text { Nmi: Micromet (approximately } 200 \text { cells, }>0.2 \\ & \text { N1a: Met in 1-3 axillary nodes* } \\ & \text { N1b: Micromet or Macromet ( }>2 \mathrm{~mm} \text { ) in ipsilateral IM } \\ & \text { nodes by SLN biopsy } \\ & \text { N1c: N1a + N1b } \\ & \text { N2a: Met in 4-9 axillary nodes* } \\ \text { N2 } & \text { N2b: Met in ipsilateral IM nodes by imaging, axilla } \\ & \text { negative } \\ \text { N3a: Met in } \geq 10 \text { axillary nodes* or in level 3 } \\ \text { (infraclavicular) axillary nodes } \\ \text { N3b: Met in IM nodes by imaging with 1 or more level } 1 \\ \text { *detected by microscopic or molecular techniques } \\ \text { Distant metastasis: Metastasis to distant organs and non-regional lymph nodes } \\ \text { N1 }\end{array}$

pathological "p" staging. Clinical staging uses information such as patient history, physical examination, and any imaging performed before the surgery and neoadjuvant treatment. Clinical staging can use biopsy results such as fine-needle aspiration (FNA), core biopsy or sentinel lymph node (SLN) biopsy. Pathological staging uses information defined at the surgery. It does not apply to patients treated with systemic or radiation treatment before surgery. Following neoadjuvant systemic therapy, post-therapy pathological staging is defined as "yp".

In prognostic staging (clinical and pathological), biomarker tests are integrated into TNM staging [9]. Biomarker tests include histological grade, ER, PR, HER2, proliferation markers (Ki-67 or mitotic count) and genomic assays.

\section{Definition of Locally Advanced Disease}

Per National Comprehensive Cancer Network (NCCN), locally advanced breast cancer describes a subset of invasive breast cancer where the initial clinical and radiologic evaluation documents advanced disease confined to the breast and regional lymph nodes [10]. Locally advanced breast cancer is also further classified as operable (Clinical stage T3, N1, M0) and inoperable (Clinical stage IIIA [except T3, N1 M0], IIIB, and IIIC). Definition of regional lymph nodes for staging purpose is ipsilateral axillary level 1 and 2, 3, internal mammary, intramammary and supraclavicular nodes [9]. NCCN and the American Joint Committee on Cancer (AJCC) considers level 3 axillary nodes as infraclavicular nodes. Lymph node metastases other than regional lymph nodes (including cervical or contralateral internal mammary or contralateral axillary lymph nodes) is considered as distant metastases.

\section{Breast Cancer Metastases}

A seed-and-soil hypothesis is believed to be the mechanism for metastases in breast cancer [18]. Disseminated cancer cells (seeds) reach a microenvironment (soil) and proliferate. Bone, lung, liver, and brain are the common sites for metastatic spread of breast cancer. Breast cancer subtypes are associated with different metastatic patterns. In triple-negative tumours, there is a higher rate of metastases to visceral organs, such as brain, lung and liver, and a lower rate of metastases to bone, whereas bone is a major site of metastasis in ER + breast cancer and HER2 + subtypes are significantly associated with higher rates of liver, brain, and lung metastases [19-22]. The metastatic patterns of lobular and ductal carcinoma of the breast are also different. Gastrointestinal system, gynecologic organs such as ovary, and peritoneum-retroperitoneum metastases are markedly more prevalent in lobular carcinoma $[23,24]$.

The main treatments for breast cancer metastasis are standard chemotherapy and targeted therapy. Targeted therapies include hormone therapy, immunological therapy and antiangiogenic therapy. In bone metastases, bone-targeted antiosteoclast agents are also given with antitumor therapy.

\section{Breast Cancer Survival Rates}

Per Surveillance Epidemiology and End Results (SEER) database, 5-year relative survival rates for localized, regional and distant involvement are 99\%, 86\% and 27\%, respectively [2]. In localized disease, there is no sign that cancer has spread outside of the breast. In regional disease, cancer has spread outside the breast to nearby structures or lymph nodes.

Per MD Anderson analysis, based on risk profile (tumour grade, ER, PR, HER2), 5-year overall survival ranges from 93.8 to $97 \%$ for stage $1,88.2$ to $97.1 \%$ for stage $\| \mathrm{A}, 91.5$ to $100 \%$ for stage IIB, 68.6 to $100 \%$ for stage IIIA, and 33.3 to $84.4 \%$ for stage IIIC breast cancer [9]. There were insufficient numbers of cases with Stage IIIB cancer for analysis.

Hormone receptor (HR)+/HER2- subtype shows the best survival (92.5\% at 4 years), followed by HR+/HER2 + (90.3\%), HR-/HER2 + (82.7\%), and finally worst survival for triple-negative subtype (77.0\%) [25].

ILC is generally associated with a good prognosis and a good response to endocrine therapy.

\section{Role of PET/CT Imaging in Breast Cancer FDG PET and NaF PET \\ Initial Staging}

Per NCCN, FDG PET/CT (FDG PET) is not indicated in the staging of early breast cancer [clinical stage I, II and operable stage III (T3 N1 M0) [ cases [10]. FDG PET is most helpful in situations where 

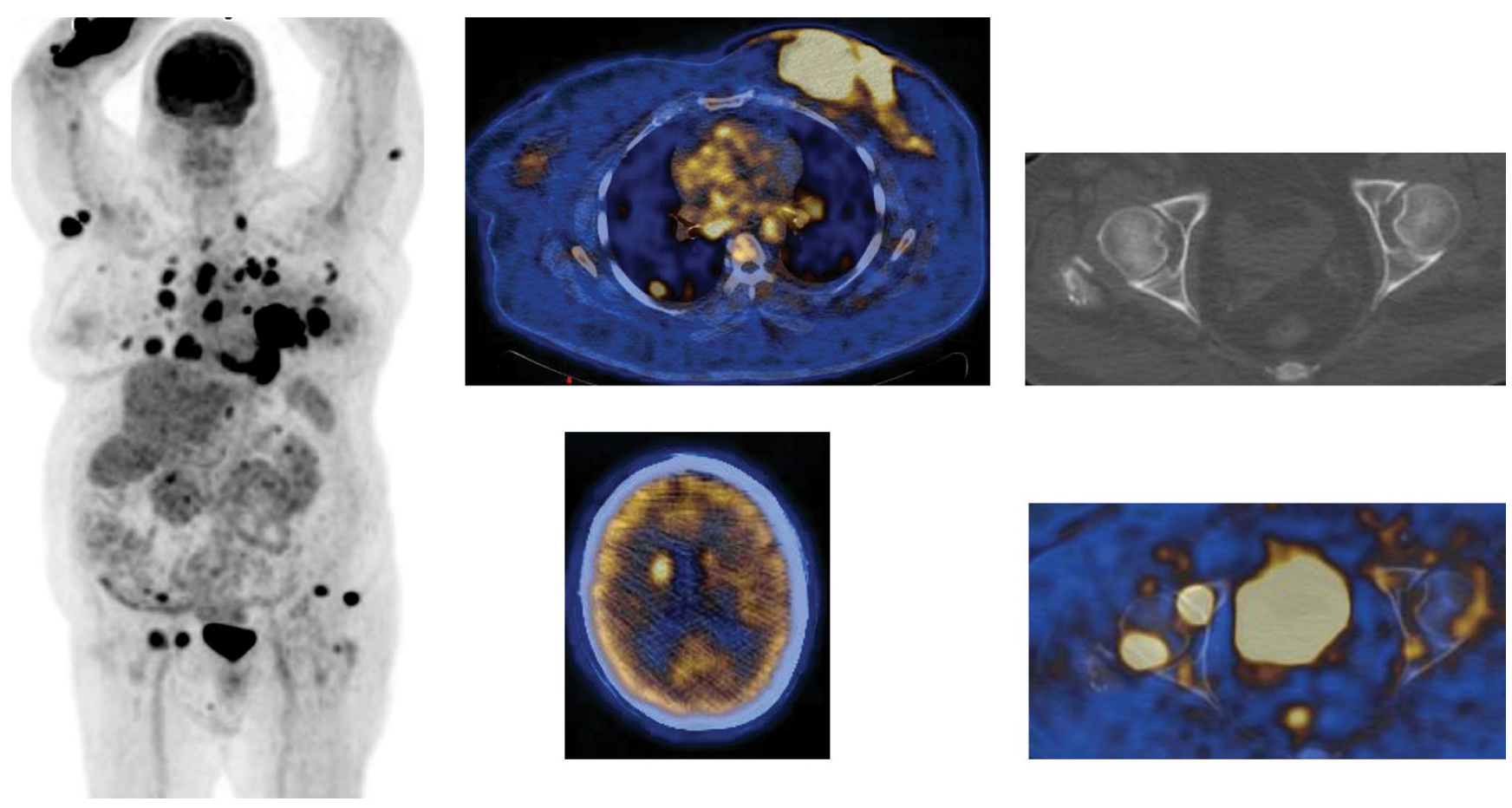

Figure 1. A 66-year-old female with newly diagnosed invasive ductal breast carcinoma. FDG PET/CT images show a large hypermetabolic (SUVmax 13.3) left breast mass invading the overlying skin and pectoralis muscle with multiple additional foci of activity within the breast and in the skin, multiple hypermetabolic lymph nodes in the left axilla, both side of the mediastinum, left supraclavicular and right retro-crural regions, multiple hypermetabolic lung nodules, multiple hypermetabolic bone lesions some with lytic changes and some without changes on CT, and a hypermetabolic focus adjacent to right caudate nucleus in the brain, all consistent with metastatic disease

standard staging studies are equivocal or suspicious for stage III and stage IV invasive breast cancer, and inflammatory breast cancer (Fig. 1) [10]. FDG PET may help identify the unsuspected regional nodal disease and/or distant metastasis in locally advanced breast cancer when used in addition to standard imaging studies [10]. FDG PET may be a useful adjunct to standard imaging of inflammatory breast cancer due to increased risk of lymph node and distant metastases [10]. Equivocal or suspicious sites identified on PET/CT should be biopsied. FDG PET/CT is not indicated in early breast cancer ( $\mathrm{Tl}$ and $\mathrm{T} 2$ unifocal tumours with clinically negative lymph nodes). In early breast cancer, sentinel lymph node (SLN) biopsy with or without SLN scintigraphy is performed to determine the pN status. In the authors' recent study, a combined assessment of SLN SPECT/CT and FDG PET/CT images helped to determine FDG uptake particularly in the SLN [26]. However, due to the limited resolution of PET scanners in detecting small-sized tumours, this technique does not seem feasible currently but may be useful in the future with the improvement in PET resolution.

FDG uptake shows a correlation with the tumour grade, histological and molecular subtypes of breast cancer and various other factors. FDG uptake is higher in higher-grade tumours than lower grade tumours [27-29]. FDG uptake is higher in IDC than ILC histological subtype [27-29]. Inflammatory breast cancers show diffuse or focal high FDG uptake. Mean SUVmax of IDC was 7.7, which ranged from 2.1 to 18.8 [30]. FDG uptake is positively correlated with the tumour size, tumour cell proliferation (Ki67 expression), nuclear atypia, mitosis counts, tumour invasive size and lymph node metastasis [28, 29, 31-34]. FDG uptake is negatively correlated with the hormonal receptor status of the tumour [28, 31]. ER-, PR-, and triple-negative subtypes show higher FDG uptake than $\mathrm{ER}+, \mathrm{PR}+, \mathrm{ER}+\mathrm{PR}+\mathrm{HER} 2+$, or $\mathrm{ER}+\mathrm{PR}+\mathrm{HER} 2-$ subtypes $[28,29,31,35,36]$. FDG uptake was significantly higher in carcinomas with a high score of HER2 expression and high levels of p53 [27, 28].

DCIS usually show low FDG uptake but symptomatic and large DCIS ( $\geq 20 \mathrm{~mm}$ ) are often visualized on FDG PET [37, 38]. Tumour cell density appears to be strongly correlated to the detection of DCIS by FDG PET [38]. FDG uptake is higher in DCIS with microinvasion than pure DCIS [36]. DCIS with micro invasions are larger, show poor prognostic factors (high grade, comedo necrosis and ER negativity), and have a worse outcome than pure DCIS [39, 40]. DCIS often coexists with IDC (IDC-DCIS) $[41,42]$. DCIS is recognized as the non-obligate precursor of IDC when it coexists with IDC [43]. Studies have reported that IDC with coexisting DCIS shows lower metastatic potential and recurrence and better overall survival than pure IDC [44, 45]. In a recent study, FDG PET/CT findings of IDC-DCIS to pure IDC [30] were compared. Multifocal breast FDG uptake and the multifocal tumour was more common in IDC-DCIS than pure IDC but there was no significant difference in standardized uptake value (SUV) of the primary tumour in IDC-DCIS and pure IDC. However, axillary metastases appeared to be more common in pure IDC than IDC-DCIS cases. In an unpublished analysis of IDC-DCIS was found a positive correlation between primary tumour grade 

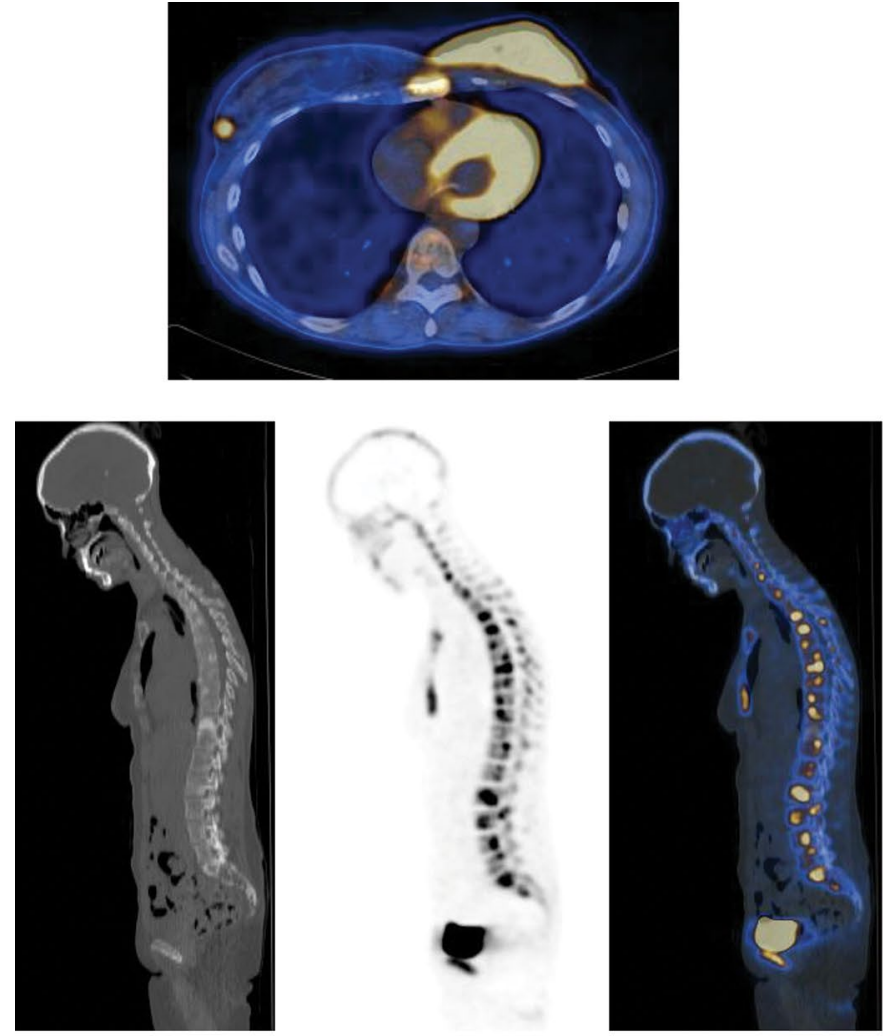

Before Chemotherapy
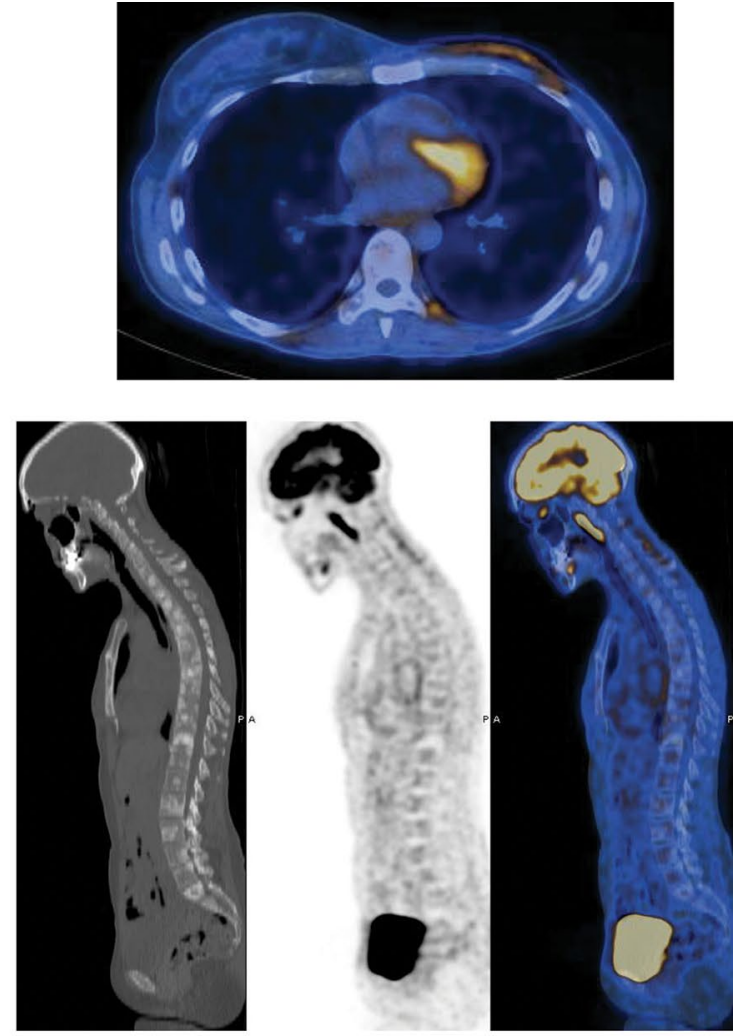

After Chemotherapy

Figure 2. FDG PET/CT images on hormone therapy with an aromatase inhibitor (before chemotherapy) and after treatment with a combination of aromatase inhibitor and chemotherapy (targeted therapy with an inhibitor of the cyclin-dependent kinases CDK4 and CDK6) (after chemotherapy) in a 41-year-old female with inflammatory breast cancer. PET images before chemotherapy show diffuse infiltration of the left breast with markedly increased metabolic activity and multiple lytic and hypermetabolic bone metastases. Note also a hypermetabolic focus in the right breast laterally. Following chemotherapy, there is a resolution of the primary tumour on both PET and CT images with only mild diffuse chest wall activity which is probably due to inflammatory changes although residual tumour cannot be excluded. There is also the resolution of hypermetabolic bone metastases and most of the lytic bone lesions become sclerotic after the treatment

and nuclear grade of the coexisting DCIS but no correlation between primary tumour SUV with the nuclear grade and the architectural subtype of the coexisting DCIS.

Bone-specific radiotracers are also known to accumulate in the breast tumours which may be due to hydroxyapatite deposition [46]. They have low sensitivity in detecting the primary tumour. In a recent study, the authors assessed $\mathrm{NaF}$ uptake in the primary breast tumours [47]. Fourteen of 31 IDC (45\%) and 3 of 4 DCIS were visible on NaF PET and 5 ILC, 2 invasive mammary carcinomas, and 1 mucinous carcinoma were not visible. In the same study, there was no correlation between NaF SUV and FDG SUV of the primary tumours.

Bone is the most common site of distant metastasis in patients with breast cancer. Bone metastases of breast cancer are most often osteolytic but can be osteoblastic or mixed and sometimes may not show any changes in CT [48]. Radionuclide bone imaging has high sensitivity in detecting bone metastases and recommended in patients with bone pain or elevated alkaline phosphatase [10]. Radionuclide bone imaging can be omitted if FDG PET/CT is positive for bone metastases [10]. NaF PET/CT provides greater spatial resolution and better image quality, resulting in better sensitivity and specificity than bone scan. In a meta-analysis study, the pooled sensitivity, and specificity of $\mathrm{NaF} \mathrm{PET/CT}$ for the detection of bone metastases were 0.98 and 0.90 , respectively with a higher overall diagnostic performance over bone scan and bone SPECT [49]. Radionuclide bone imaging is more sensitive for the detection of sclerotic osseous metastases whereas FDG PET is more sensitive for the detection of lytic osseous metastases. In untreated patients, bone metastases of ILC were more commonly sclerotic and demonstrated low FDG uptake, whereas bone metastases of IDC were more commonly lytic and showed higher FDG uptake [50].

CT has higher sensitivity than PET and PET/MR in detecting pulmonary lesions, particularly subcentimetric lesions [51]. PET underestimates the metabolic activity of the subcentimetric lung nodules due to partial volume averaging. Small lung nodules located in the periphery of the lungs, particularly near the diaphragm, may also be affected by respiratory motion which causes misregistration of CT and PET images and sub-optimal attenuation correction with underestimation of metabolic activity of the nodules. 


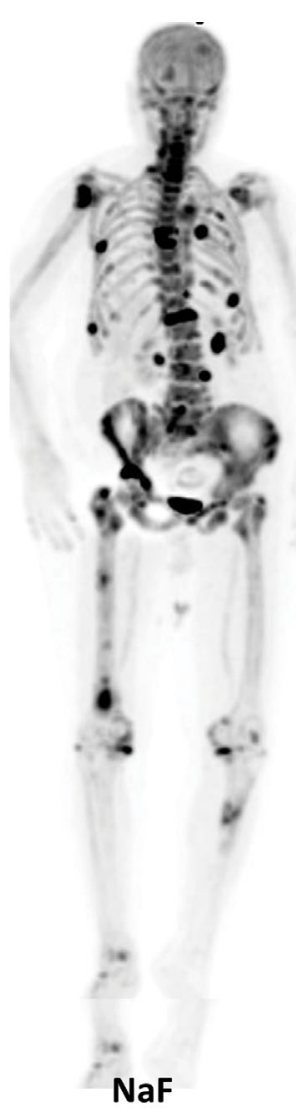

$\mathrm{NaF}$

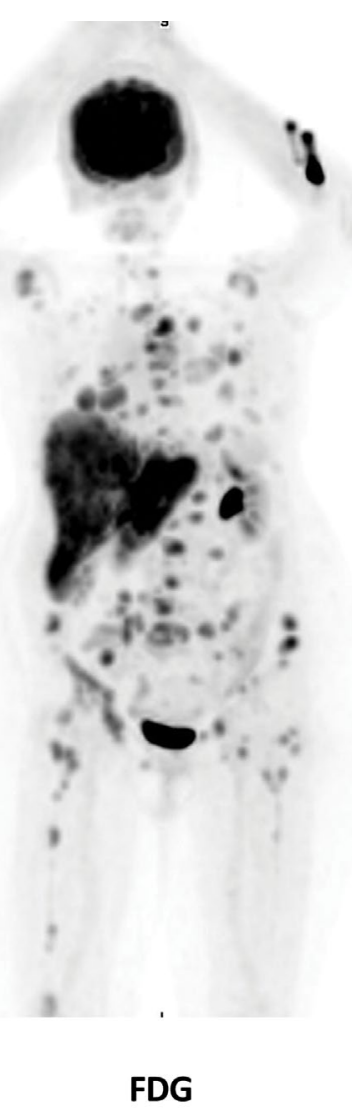

FDG
FDG
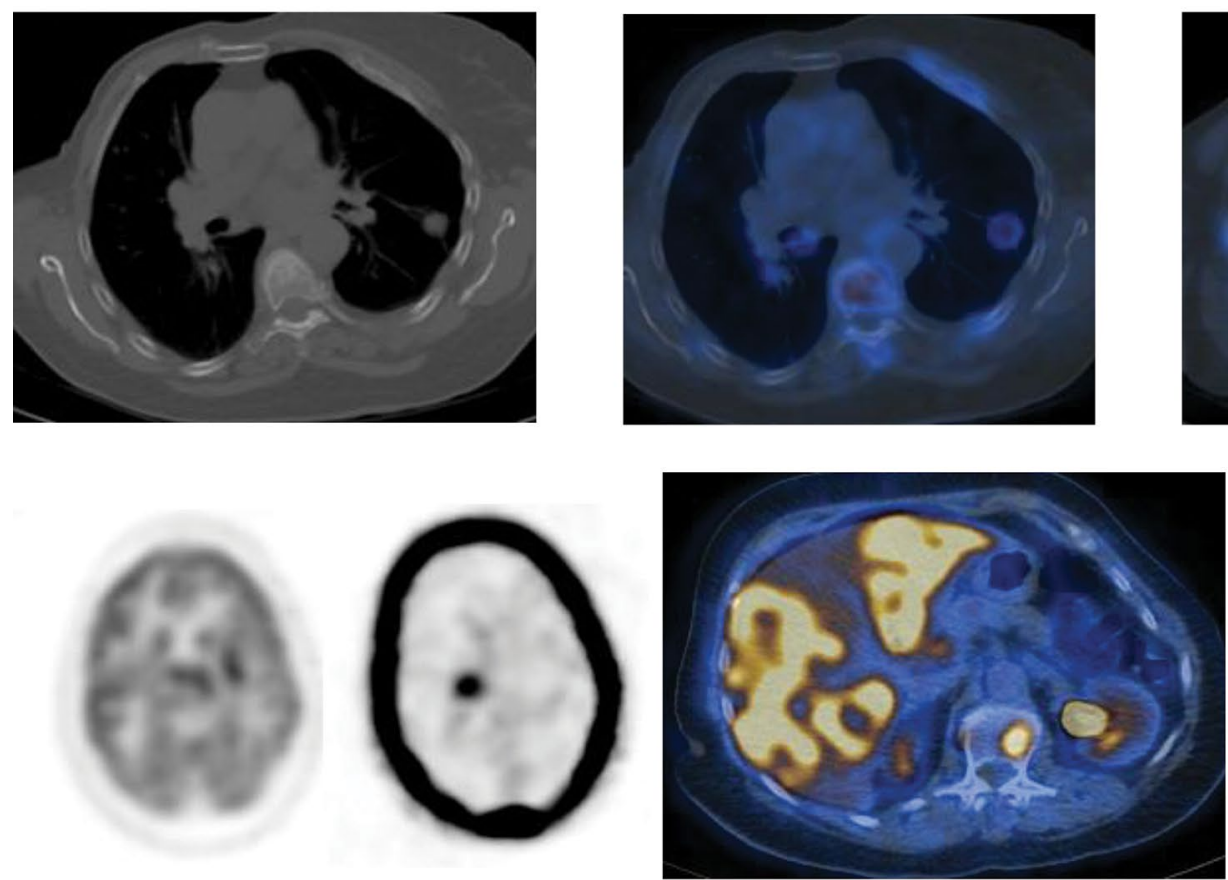

FDG
$\mathrm{NaF}$
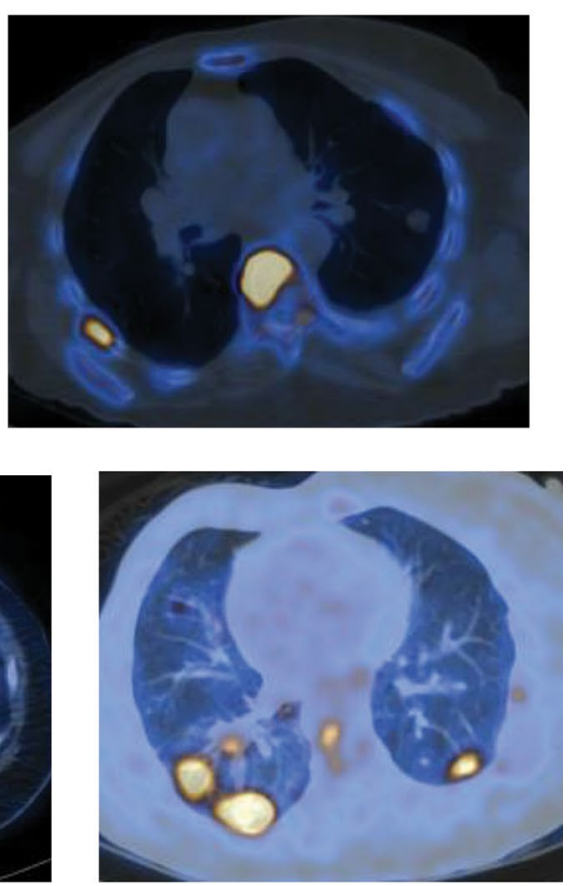

FDG

Figure 3. A 72-year-old female with a history of invasive ductal breast cancer operated and received chemotherapy 4 years before the PET scan. The patient has clinical symptoms and radiological findings highly suspicious for tumour recurrence. FDG PET/CT images show extensive metastatic disease in the liver and multiple foci of hypermetabolic bone metastases and multiple bilateral lung metastases. There is also reduced uptake in the right thalamus posteriorly and increased uptake adjacent to left caudate, highly suspicious for metastases. NaF PET images show multiple bone metastases and focal uptake corresponding to the area of reduced uptake in right thalamus on FDG PET. Uptake pattern in the bone metastases is different on FDG and NaF PET images with NaF PET showing uptake in sclerotic lesions (arrow) whereas FDG PET in lytic lesions (not shown in the figure) 
In autopsy studies, brain metastases were present in 15\% to $35 \%$ of patients with breast cancer, and some of them were asymptomatic before death [52]. Due to high FDG uptake in the grey matter of the brain and low metabolic activity of some of the brain metastases of breast cancer, the sensitivity of FDG PET is lower than diagnostic CT, MRI and PET/MR [53-55]. Cerebellum and frontal lobes are reported to be the most common sites of metastasis [56] Breast cancer metastasis in the brain could be hypermetabolic, ring-like or hypometabolic [54, 55].

Liver metastases develop in approximately $50 \%$ of patients with breast cancer [57]. MRI and PET/MR has higher sensitivity than diagnostic CT and FDG PET/CT in detecting small liver metastases [53, 58, 59]. Breast carcinoma metastases are generally hypo-vascular, but occasionally they can be hyper-vascular on contrast-enhanced MRI [60]. Background liver activity on FDG PET may reduce the detection of small metastatic foci. Dual time point FDG PET imaging may increase the detection of liver metastases of breast cancer [61].

\section{Assessing Response to Treatment}

PET/CT imaging is very useful for prediction of treatment response as early as after the first cycle of chemotherapy and after completion of chemotherapy (Fig. 2).

Studies have shown that FDG PET imaging early in the course of the chemotherapy helps to differentiate responders from non-responders [62-66]. A reduction in tumour FDG uptake supports the efficiency of the treatment whereas no change or further increase in tumour FDG uptake indicates that the treatment is ineffective.

To assess early treatment response, a period of $1 \pm 2$ weeks between completion of the chemotherapy cycle and FDG PET scan is recommended to avoid transient increases and decreases in tumour FDG uptake [67]. To assess the complete treatment response, International Harmonization Project (IHP) recommends waiting 6-8 weeks after the last cycle of chemotherapy [68].

Positron Emission Tomography (PET) Response Criteria in Solid Tumours (PERCIST) recommends $\mathrm{a} \geq 30 \%$ decrease in tumour SUV as compared to baseline PET study as a cut-off value for partial metabolic response in solid tumours [69].

Definition of FDG tumour response in malignancies by European Organisation for Research and Treatment of Cancer (EORTC) [67]:

Progressive metabolic disease: Increase in tumour SUV greater than $25 \%$ and visible increase in the size of the tumour (> 20\% in longest diameter) and appearance of new lesions as compared to baseline FDG PET scan.

Stable metabolic disease: Decrease in tumour SUV less than $15 \%$ or increase in tumour SUV less than $25 \%$ and no visible change in tumour size.

Partial Metabolic Response: A reduction of minimum 15-25\% in tumour SUV after 1 cycle of treatment and greater than $25 \%$ after more cycles of treatment.

Complete response: Complete resolution of tumour FDG uptake so that it was indistinguishable from surrounding normal tissue.

Currently, there is not an effective study for accurate assessment of response to therapy of bone metastases of breast cancer. Lytic lesions usually become sclerotic after systemic treatment.
Non-FDG avid sclerotic lesions may represent treated metastasis and healing response rather than the active tumour. Several studies have suggested that a change in SUV on FDG PET can predict disease response or progression. In a study of sequential FDG PET/CT imaging for monitoring bone metastasis of breast cancer during therapy, an increase in FDG uptake was correlated with lytic changes on the CT images and indicated progression of the disease [70]. However, early metabolic flare can also be seen with FDG PET. Increase in FDG uptake was observed 7-10 days after initiation of tamoxifen therapy in the majority of the metastatic bone lesions of the breast cancer responders [71]. Flare phenomenon is a significant problem in radionuclide bone imaging studies with temporary increases in activity and size of lesions or appearance of new lesions. To avoid misinterpretation of the flare reaction it is recommended to wait 6 months before evaluating the response, by MD Anderson criteria, or repeating the study [72]. Due to long waiting time, radionuclide bone imaging is not useful in early response assessment to treatments. It is also not useful in lytic or diffuse sclerotic (super scan) disease when assessing response to treatment [72]. Per EORTC, whole body or axial skeleton, MRI offers the best single modality of assessing response to therapy in bone metastases from breast cancer [72]. MRI is also not affected by flare response and has a potential for early response assessment to treatments [73]. As the changes in bone lesions are often difficult to assess on plain or cross-sectional radiology or radionuclide bone imaging, clinical symptoms and serum tumour markers (e.g., CEA, CA15-3, CA27.29) can help to determine if there is disease progression in bone-dominant metastatic disease [10].

\section{Detecting Tumour Recurrence}

Various factors affect breast cancer recurrence. Tumour size larger than $2 \mathrm{~cm}$, axillary lymph node involvement, negative oestrogen and progesterone receptor status, and high tumour grade is associated with increased risk of loco-regional recurrence and metastases [74]. Breast cancer recurrence rate is approximately $30 \%$, depending on the initial extent of the tumour and various other factors [75].

Studies have shown that FDG PET/CT imaging is superior to conventional imaging in detecting breast cancer recurrence (Figure 3). In breast cancer patients with rising Ca 15-3 tumour marker with negative conventional imaging, FDG PET/CT detected tumour deposits in 40 of 89 patients, in the chest wall, internal mammary nodes, lungs, liver and skeleton [76]. The sensitivity and specificity of FDG PET and conventional modalities were $84 \%$ and $78 \%$ versus $63 \%$ and $61 \%$, respectively, in breast cancer patients with suspicion of recurrence [77]. In patients with confirmed breast cancer recurrence, conventional imaging was positive in $88 \%$ of the cases, whereas FDG PET/CT was positive in 95\% [78]. FDG PET/CT had also a higher negative predictive value (86\% versus $54 \%$ ) and positive predictive value (95\% versus $70 \%$ ) than conventional imaging in the same study. In another study, FDG PET/CT was better than conventional imaging in detecting locoregional disease or distant metastases in breast cancer patients suspected of tumour recurrence [79]. In a study comparing FDG PET/CT to whole-body MRI, PET/CT detected more lymph node metastases (21 vs 16) whereas whole-body MRI was more precise in the detection of distant metastases (154 vs 147) [80]. 
However, a meta-analysis study showed that mediastinal and loco-regional lymph nodes represented the most common site for false-positive FDG PET/CT [81]. In 17 patients with breast cancer recurrence, FDG PET/MR and FDG PET/CT were positive in all patients with slightly more lesions detected by FDG PET/MR [82]. Per NCCN recommendation, FDG PET/CT can be performed at the same time as diagnostic CT and is most helpful in situations where standard studies are equivocal or suspicious [10].

\section{Predicting Prognosis and Survival}

Studies have shown that baseline FDG PET imaging has a prognostic value. Tumours with high SUV showed higher relapse and mortality rate compared to those with low SUV [28]. In ER+/HER2- M0 patients, tumour SUV and total lesion glycolysis were associated with shorter event-free survival [83]. Three-year event-free survival was $49 \%$ in patients with tumour SUV of 10 versus $92 \%$ in patients with tumour SUV $<10$ [83]. FDG-PET determined parameters (maximum SUV, peak SUV and total lesion glycolysis) appeared to provide prognostic survival information in patients with recurrent breast cancer [84]. In patients with low and high metabolic tumour volume, 5-year progression-free survival was 81.0 and $14.3 \%$, and 5 -year overall survival was $88.5 \%$ and $43.6 \%$, respectively [85].

\section{Other PET Tracers}

ER expression is associated with a more favourable prognosis in breast cancer. ER status of the tumour predicts the likelihood of response to ER-targeted therapy [86]. ${ }^{18} \mathrm{~F}$-fluoroestradiol is an investigational PET tracer which binds to ER receptors. FES PET helps to determine the presence and amount of ER expression and predicts response to hormone therapy [87]. FES uptake is influenced by the site of metastasis. FES uptake in bone metastases was higher than in lymph node and lung metastases [88]. As the FES is highly extracted and metabolized by the liver, FES PET may have low sensitivity in detecting liver metastases. Studies suggest that up to $30 \%$ of patients may lose ER expression after undergoing endocrine therapy.

Approximately $20 \%$ of invasive ductal breast malignancies are classified as HER2-positive [89]. HER2+ breast cancer receives specific targeted HER2 therapies (humanized mAbs against HER2). ${ }^{89}$ Zr-trastuzumab (radiolabelled herceptin) binds with high affinity to the extracellular domain of the HER2 receptor. In a clinical trial, ${ }^{89} \mathrm{Zr}$-trastuzumab showed excellent tumour uptake and visualization of HER2-positive metastatic lesions [90].

18F-Fluorothymidine (FLT) is a biomarker reflecting cell proliferation. There is a good correlation between the FLT uptake and the Ki-67 labelling index in breast cancer [91]. FLT PET seems to be a good predictor of response to treatment, particularly early response [92].

There are various other potential PET radiotracers such as ${ }^{18} \mathrm{~F}$-galacto-RGD for angiogenesis, ${ }^{18} \mathrm{~F}$-annexin $\mathrm{V}$ for apoptosis, ${ }^{89} \mathrm{Zr}$-anti-gH2AX-TAT for cell death, and ${ }^{18} \mathrm{~F}$-FMISO for hypoxia. RGD PET parameters were found to be significantly higher in HER2-positive patients [93]. RGD PET identified all invasive carcinomas, with SUVs ranging from 1.4 to 8.7 [94]. Lymph-node metastases were detected in 3 of 8 patients and SUVs in distant metastases were heterogeneous [94]. FMISO PET/CT was found to be useful for predicting primary endocrine resistance in ER+ breast cancer [95].
It was reported that $60 \%$ of breast cancer cases exhibited PSMA-positive endothelia with higher expression rates in the higher grade, NST subtype, HER2 +, and hormone receptor-negative tumours [96]. ${ }^{68} \mathrm{Ga}-\mathrm{PSMA}$ ligand uptake was reported in primary breast tumour and its metastases [97]. In 19 patients with breast cancer, there was PSMA uptake in $84 \%$ of tumour lesions with higher uptake in distant metastases than primary or local recurrence [98].

\section{Conclusion}

Breast cancer is the most common cancer among women and also one of the most common indications of PET imaging. FDG and NaF are commonly used PET tracers in breast cancer mainly for initial staging, treatment response assessment and in detecting tumour recurrence. Various other more specific PET tracers targeting ER, HER2, cell proliferation, angiogenesis, cell death, apoptosis and hypoxia are at investigational level.

\section{References}

1. World Health Organization (2019). Breast cancer: Early diagnosis and screening. https://www.who.int/cancer/ prevention/diagnosis-screening/breast-cancer/en/ (18.04.2019).

2. American Cancer Society. Definitions. 2020, doi: 10.32388/w3jpuc.

3. Guinebretière JM, Menet E, Tardivon A, et al. Normal and pathological breast, the histological basis. Eur J Radiol. 2005; 54(1): 6-14, doi: 10.1016/j. ejrad.2004.11.020, indexed in Pubmed: 15797289.

4. Suami H, Pan WR, Mann GB, et al. The lymphatic anatomy of the breast and its implications for sentinel lymph node biopsy: a human cadaver study. Ann Surg Oncol. 2008; 15(3): 863-871, doi: 10.1245/s10434-007-9709-9, indexed in Pubmed: 18043970.

5. Urban JA. Management of operable breast cancer: the surgeon's view. Cancer. 1978; 42(4): 2066-2077, doi: 10.1002/1097-0142(197810)42:4<2066::ai d-cncr2820420458>3.0.co;2-v, indexed in Pubmed: 101302.

6. Elmadahm AA, Gill PG, Bochner M, et al. Mammary lymphoscintigraphy in breast cancer. J Nucl Med. 1995; 36(10): 1775-1780, indexed in Pubmed: 7562041.

7. Oeffinger K, Fontham E, Etzioni R, et al. Breast Cancer Screening for Women at Average Risk. JAMA. 2015; 314(15): 1599, doi: 10.1001/jama.2015.12783.

8. Gülsün M, Demirkazik FB, Ariyürek M. Evaluation of breast microcalcifications according to Breast Imaging Reporting and Data System criteria and Le Gal's classification. Eur J Radiol. 2003; 47(3): 227-231, doi: 10.1016/s0720-048x(02)00181-x, indexed in Pubmed: 12927667.

9. AJCC Cancer Staging Manual, Eighth Edition (c) The American College of Surgeons (ACS), Chicago, Illinois. Last updated 01. ; 25: 2018.

10. NCCN Clinical Practice Guidelines in Oncology (NCCN Guidelines). National Comprehensive Cancer Network. Version 4 2017-February. ; 7: 2018.

11. Arps DP, Healy P, Zhao L, et al. Invasive ductal carcinoma with lobular features: a comparison study to invasive ductal and invasive lobular carcinomas of the breast. Breast Cancer Res Treat. 2013; 138(3): 719-726, doi: 10.1007/s10549-013-2493-2, indexed in Pubmed: 23535842.

12. Malhotra GK, Zhao X, Band $\mathrm{H}$, et al. Histological, molecular and functional subtypes of breast cancers. Cancer Biol Ther. 2010; 10(10): 955-960, doi: 10.4161/cbt.10.10.13879, indexed in Pubmed: 21057215.

13. Dawood S, Merajver SD, Viens P, et al. International expert panel on inflammatory breast cancer: consensus statement for standardized diagnosis and treatment. Ann Oncol. 2011; 22(3): 515-523, doi: 10.1093/annonc/mdq345, indexed in Pubmed: 20603440.

14. McCart Reed AE, Kutasovic JR, Lakhani SR, et al. Invasive lobular carcinoma of the breast: morphology, biomarkers and 'omics. Breast Cancer Res. 2015; 17: 12, doi: 10.1186/s13058-015-0519-x, indexed in Pubmed: 25849106. 
15. Dunnwald L, Rossing M, Li C. Hormone receptor status, tumor characteristics, and prognosis: a prospective cohort of breast cancer patients. Breast Cancer Research. 2007; 9(1), doi: 10.1186/bcr1639.

16. Dai X, Xiang L, Li T, et al. Cancer Hallmarks, Biomarkers and Breast Cancer Molecular Subtypes. J Cancer. 2016; 7(10): 1281-1294, doi: 10.7150/jca.13141, indexed in Pubmed: 27390604.

17. Duffy MJ, Synnott NC, Crown J. Mutant p53 in breast cancer: potential as a therapeutic target and biomarker. Breast Cancer Res Treat. 2018; 170(2): 213-219, doi: 10.1007/s10549-018-4753-7, indexed in Pubmed: 29564741.

18. Langley RR, Fidler IJ. The seed and soil hypothesis revisited--the role of tumor-stroma interactions in metastasis to different organs. Int J Cancer. 2011; 128(11): 2527-2535, doi: 10.1002/ijc.26031, indexed in Pubmed: 21365651.

19. Xiao W, Zheng S, Yang A, et al. Breast cancer subtypes and the risk of distant metastasis at initial diagnosis: a population-based study. Cancer Manag Res. 2018; 10: 5329-5338, doi: 10.2147/CMAR.S176763, indexed in Pubmed: 30464629

20. Soni A, Ren Z, Hameed O, et al. Breast cancer subtypes predispose the site of distant metastases. Am J Clin Pathol. 2015; 143(4): 471-478, doi: 10.1309/AJCPYO5FSV3UPEXS, indexed in Pubmed: 25779997.

21. Smid M, Wang Y, Zhang Yi, et al. Subtypes of breast cancer show preferential site of relapse. Cancer Res. 2008; 68(9): 3108-3114, doi: 10.1158/00085472.CAN-07-5644, indexed in Pubmed: 18451135.

22. Gerratana L, Fanotto V, Bonotto M, et al. Pattern of metastasis and outcome in patients with breast cancer. Clin Exp Metastasis. 2015; 32(2): 125-133, doi: 10.1007/s10585-015-9697-2, indexed in Pubmed: 25630269.

23. Mathew A, Rajagopal PS, Villgran V, et al. Distinct Pattern of Metastases in Patients with Invasive Lobular Carcinoma of the Breast. Geburtshilfe Frauenheilkd. 2017; 77(6): 660-666, doi: 10.1055/s-0043-109374, indexed in Pubmed: 28757653.

24. Borst MJ, Ingold JA. Metastatic patterns of invasive lobular versus invasive ductal carcinoma of the breast. Surgery. 1993; 114(4): 637-41; discussion 641, indexed in Pubmed: 8211676.

25. Howlader N, Cronin KA, Kurian AW, et al. Differences in Breast Cancer Survival by Molecular Subtypes in the United States. Cancer Epidemiol Biomarkers Prev. 2018; 27(6): 619-626, doi: 10.1158/1055-9965.EPI-170627, indexed in Pubmed: 29593010.

26. Sarikaya I, Sarikaya A. Assessing F-FDG Uptake in the Sentinel Lymph Node in Breast Cancer. J Nucl Med Technol. 2019; 47(2): 149-153, doi: 10.2967/jnmt.118.219758, indexed in Pubmed: 30413593

27. Crippa F, Seregni E, Agresti R, et al. Association between [18F]fluorodeoxyglucose uptake and postoperative histopathology, hormone receptor status, thymidine labelling index and p53 in primary breast cancer: a preliminary observation. Eur J Nucl Med. 1998; 25(10): 1429-1434, doi: 10.1007/s002590050319, indexed in Pubmed: 9818284

28. Ueda S, Tsuda H, Asakawa H, et al. Clinicopathological and prognostic relevance of uptake level using $18 \mathrm{~F}$-fluorodeoxyglucose positron emission tomography/computed tomography fusion imaging (18F-FDG PET/CT) in primary breast cancer. Jpn J Clin Oncol. 2008; 38(4): 250-258, doi: 10.1093/jjco/hyn019, indexed in Pubmed: 18407934

29. Wang CL, MacDonald LR, Rogers JV, et al. Positron emission mammography: correlation of estrogen receptor, progesterone receptor, and human epidermal growth factor receptor 2 status and 18F-FDG. AJR Am J Roentgenol. 2011; 197(2): W247-W255, doi: 10.2214/AJR.11.6478, indexed in Pubmed: 21785049.

30. Sarikaya I, Sarikaya A, Albatineh AN, et al. Is there a difference in FDG PET findings of invasive ductal carcinoma of the breast with and without coexisting DCIS? Asia Ocean J Nucl Med Biol. 2020; 8: 27-35.

31. Jo I, Zeon SK, Kim SH, et al. Correlation of Primary Tumor FDG Uptake with Clinicopathologic Prognostic Factors in Invasive Ductal Carcinoma of the Breast. Nucl Med Mol Imaging. 2015; 49(1): 19-25, doi: 10.1007/s13139014-0296-y, indexed in Pubmed: 25774234.
32. Kim JY, Lee SH, Kim S, et al. Tumour 18 F-FDG Uptake on preoperative PET/CT may predict axillary lymph node metastasis in ER-positive/HER2-negative and HER2-positive breast cancer subtypes. Eur Radiol. 2015; 25(4): 1172-1181, doi: 10.1007/s00330-014-3452-y, indexed in Pubmed: 25298170.

33. Ege Aktas G, Taştekin E, Sarikaya A. Assessment of biological and clinical aggressiveness of invasive ductal breast cancer using baseline 18F-FDG PET/CT-derived volumetric parameters. Nucl Med Commun. 2018; 39(1): 8393, doi: 10.1097/MNM.0000000000000779, indexed in Pubmed: 29135722.

34. Gil-Rendo A, Martínez-Regueira F, Zornoza G, et al. Association between [18F]fluorodeoxyglucose uptake and prognostic parameters in breast cancer. Br J Surg. 2009; 96(2): 166-170, doi: 10.1002/bjs.6459, indexed in Pubmed: 19160365.

35. Groheux D, Giacchetti S, Moretti JL, et al. Correlation of high 18F-FDG uptake to clinical, pathological and biological prognostic factors in breast cancer. Eur J Nucl Med Mol Imaging. 2011; 38(3): 426-435, doi: 10.1007/s00259010-1640-9, indexed in Pubmed: 21057787

36. Yoon HJ, Kim Y, Kim BS. Intratumoral metabolic heterogeneity predicts invasive components in breast ductal carcinoma in situ. Eur Radiol. 2015; 25(12): 3648-3658, doi: 10.1007/s00330-015-3761-9, indexed in Pubmed: 26063655.

37. Avril N, Menzel M, Dose J, et al. Glucose metabolism of breast cancer assessed by 18F-FDG PET: histologic and immunohistochemical tissue analysis. J Nucl Med. 2001; 42(1): 9-16, indexed in Pubmed: 11197987

38. Fujioka T, Kubota K, Toriihara A, et al. Tumor characteristics of ductal carcinoma in situ of breast visualized on [F-18] fluorodeoxyglucose-positron emission tomography/computed tomography: Results from a retrospective study. World J Radiol. 2016; 8(8): 743-749, doi: 10.4329/wjr.v8.i8.743, indexed in Pubmed: 27648168

39. de Mascarel I, MacGrogan G, Mathoulin-Pélissier S, et al. Breast ductal carcinoma in situ with microinvasion: a definition supported by a long-term study of 1248 serially sectioned ductal carcinomas. Cancer. 2002; 94(8): 2134-2142, doi: 10.1002/cncr.10451, indexed in Pubmed: 12001109.

40. Yu KD, Wu LM, Liu GY, et al. Different distribution of breast cancer subtypes in breast ductal carcinoma in situ (DCIS), DCIS with microinvasion, and DCIS with invasion component. Ann Surg Oncol. 2011; 18(5): 1342-1348, doi: 10.1245/s10434-010-1407-3, indexed in Pubmed: 21042943.

41. Jo BH, Chun YK. Heterogeneity of invasive ductal carcinoma: proposal for a hypothetical classification. J Korean Med Sci. 2006; 21(3): 460-468, doi: 10.3346/jkms.2006.21.3.460, indexed in Pubmed: 16778390.

42. Logullo AF, Godoy AB, Mourão-Neto M, et al. Presence of ductal carcinoma in situ confers an improved prognosis for patients with T1NOMO invasive breast carcinoma. Braz J Med Biol Res. 2002; 35(8): 913-919, doi: 10.1590/s0100-879x2002000800008, indexed in Pubmed: 12185383.

43. Pinder SE, Ellis IO. The diagnosis and management of pre-invasive breast disease: ductal carcinoma in situ (DCIS) and atypical ductal hyperplasia (ADH)--current definitions and classification. Breast Cancer Res. 2003; 5(5): 254-257, doi: 10.1186/bcr623, indexed in Pubmed: 12927035.

44. Dieterich M, Hartwig F, Stubert J, et al. Accompanying DCIS in breast cancer patients with invasive ductal carcinoma is predictive of improved local recurrence-free survival. Breast. 2014; 23(4): 346-351, doi: 10.1016/j. breast.2014.01.015, indexed in Pubmed: 24559611.

45. Wong H, Lau S, Yau T, et al. Presence of an in situ component is associated with reduced biological aggressiveness of size-matched invasive breast cancer. Br J Cancer. 2010; 102: 1391-6.

46. Berg G, Kalisher L, Osmond J, et al. 99mTc-Diphosphonate Concentration in Primary Breast Carcinoma. Radiology. 1973; 109(2): 393-394, doi: 10.1148/109.2.393.

47. Sarikaya I, Sharma P, Sarikaya A. F-18 fluoride uptake in primary breast cancer. Ann Nucl Med. 2018; 32(10): 678-686, doi: 10.1007/s12149-0181294-4, indexed in Pubmed: 30178199

48. Kozlow W, Guise TA. Breast cancer metastasis to bone: mechanisms of osteolysis and implications for therapy. J Mammary Gland Biol Neoplasia. 
2005; 10(2): 169-180, doi: 10.1007/s10911-005-5399-8, indexed in Pubmed: 16025223 .

49. Sheikhbahaei S, Jones KM, Werner RA, et al. F-NaF-PET/CT for the detection of bone metastasis in prostate cancer: a meta-analysis of diagnostic accuracy studies. Ann Nucl Med. 2019; 33(5): 351-361, doi: 10.1007/s12149019-01343-y, indexed in Pubmed: 30877561

50. Dashevsky BZ, Goldman DA, Parsons M, et al. Appearance of untreated bone metastases from breast cancer on FDG PET/CT: importance of histologic subtype. Eur J Nucl Med Mol Imaging. 2015; 42(11): 1666-1673, doi: 10.1007/s00259-015-3080-z, indexed in Pubmed: 25971426.

51. Rauscher I, Eiber M, Fürst S, et al. PET/MR imaging in the detection and characterization of pulmonary lesions: technical and diagnostic evaluation in comparison to PET/CT. J Nucl Med. 2014; 55(5): 724-729, doi: 10.2967/jnumed.113.129247, indexed in Pubmed: 24652827.

52. Martin AM, Cagney DN, Catalano PJ, et al. Brain Metastases in Newly Diagnosed Breast Cancer: A Population-Based Study. JAMA Oncol. 2017; 3(8): 1069-1077, doi: 10.1001/jamaoncol.2017.0001, indexed in Pubmed: 28301662.

53. Gaeta CM, Vercher-Conejero JL, Sher AC, et al. Recurrent and metastatic breast cancer PET, PET/CT, PET/MRI: FDG and new biomarkers. Q J Nucl Med Mol Imaging. 2013; 57(4): 352-366, indexed in Pubmed: 24322792.

54. Bochev P, Klisarova A, Kaprelyan A, et al. Brain metastases detectability of routine whole body (18)F-FDG PET and low dose CT scanning in 2502 asymptomatic patients with solid extracranial tumors. Hell J Nucl Med. 2012; 15(2): 125-129, doi: 10.1967/s002449910030, indexed in Pubmed: 22741148

55. Kitajima K, Nakamoto $\mathrm{Y}$, Okizuka H, et al. Accuracy of whole-body FDG-PET/CT for detecting brain metastases from non-central nervous system tumors. Ann Nucl Med. 2008; 22(7): 595-602, doi: 10.1007/s12149008-0145-0, indexed in Pubmed: 18756362

56. Rostami R, Mittal S, Rostami P, et al. Brain metastasis in breast cancer: a comprehensive literature review. J Neurooncol. 2016; 127(3): 407-414, doi: 10.1007/s11060-016-2075-3, indexed in Pubmed: 26909695.

57. He ZY, Wu SG, Peng F, et al. Up-Regulation of RFC3 Promotes Triple Negative Breast Cancer Metastasis and is Associated With Poor Prognosis Via EMT. Transl Oncol. 2017; 10(1): 1-9, doi: 10.1016/j.tranon.2016.10.004, indexed in Pubmed: 27888707

58. Patterson SA, Khalil HI, Panicek DM, et al. Hepatic lesions deemed too small to characterize at $\mathrm{CT}$ : prevalence and importance in women with breast cancer. Radiology. 2005; 235(3): 872-878, doi: 10.1148/radiol.2353041099, indexed in Pubmed: 15833992.

59. Melsaether AN, Raad RA, Pujara AC, et al. Comparison of Whole-Body (18)F FDG PET/MR Imaging and Whole-Body (18)F FDG PET/CT in Terms of Lesion Detection and Radiation Dose in Patients with Breast Cancer. Radiology. 2016; 281(1): 193-202, doi: 10.1148/radiol.2016151155, indexed in Pubmed: 27023002.

60. Namasivayam S, Martin DR, Saini S. Imaging of liver metastases: MRI. Cancer Imaging. 2007; 7: 2-9, doi: 10.1102/1470-7330.2007.0002, indexed in Pubmed: 17293303

61. Annovazzi A, Rea S, Vici P, et al. Dual-time 18F-FDG PET/CT for the detection of liver metastases in breast cancer. Nucl Med Commun. 2018; 39(12): 11831189, doi: 10.1097/MNM.0000000000000918, indexed in Pubmed: 30216230.

62. Wahl RL, Zasadny K, Helvie M, et al. Metabolic monitoring of breast cancer chemohormonotherapy using positron emission tomography: initial evaluation. J Clin Oncol. 1993; 11(11): 2101-2111, doi: 10.1200/JCO.1993.11.11.2101, indexed in Pubmed: 8229124.

63. Schelling M, Avril N, Nährig J, et al. Positron emission tomography using [(18) F]Fluorodeoxyglucose for monitoring primary chemotherapy in breast cancer. J Clin Oncol. 2000; 18(8): 1689-1695, doi: 10.1200/JCO.2000.18.8.1689, indexed in Pubmed: 10764429.

64. Smith IC, Welch AE, Hutcheon AW, et al. Positron emission tomography using [(18)F]-fluorodeoxy-D-glucose to predict the pathologic response of breast cancer to primary chemotherapy. J Clin Oncol. 2000; 18(8): 16761688, doi: 10.1200/JCO.2000.18.8.1676, indexed in Pubmed: 10764428.

65. Rousseau C, Devillers A, Sagan C, et al. Monitoring of early response to neoadjuvant chemotherapy in stage II and III breast cancer by [18F]fluorodeoxyglucose positron emission tomography. J Clin Oncol. 2006; 24(34): 5366-5372, doi: 10.1200/JCO.2006.05.7406, indexed in Pubmed: 17088570.

66. Schwarz-Dose J, Untch M, Tiling R, et al. Monitoring primary systemic therapy of large and locally advanced breast cancer by using sequential positron emission tomography imaging with [18F]fluorodeoxyglucose. J Clin Oncol. 2009; 27(4): 535-541, doi: 10.1200/JCO.2008.17.2650, indexed in Pubmed: 19075273.

67. Young $\mathrm{H}$, Baum R, Cremerius $U$, et al. Measurement of clinical and subclinical tumour response using [18F]-fluorodeoxyglucose and positron emission tomography: review and 1999 EORTC recommendations. European Journal of Cancer. 1999; 35(13): 1773-1782, doi: 10.1016/s0959-8049(99)00229-4.

68. Juweid ME, Stroobants S, Hoekstra OS, et al. Imaging Subcommittee of International Harmonization Project in Lymphoma. Use of positron emission tomography for response assessment of lymphoma: consensus of the Imaging Subcommittee of International Harmonization Project in Lymphoma. J Clin Oncol. 2007; 25(5): 571-578, doi: 10.1200/JCO.2006.08.2305, indexed in Pubmed: 17242397.

69. Wahl RL, Jacene $H$, Kasamon $\mathrm{Y}$, et al. From RECIST to PERCIST: Evolving Considerations for PET Response Criteria in Solid Tumors. Journal of Nuclear Medicine. 2009; 50(Suppl_1), doi: 10.2967/jnumed.108.057307.

70. Katayama T, Kubota K, Machida $Y$, et al. Evaluation of sequential FDG-PET/CT for monitoring bone metastasis of breast cancer during therapy: correlation between morphological and metabolic changes with tumor markers. Ann Nucl Med. 2012; 26(5): 426-435, doi: 10.1007/s12149012-0595-2, indexed in Pubmed: 22477261.

71. Mortimer JE, Dehdashti F, Siegel BA, et al. Metabolic flare: indicator of hormone responsiveness in advanced breast cancer. J Clin Oncol. 2001; 19(11): 2797-2803, doi: 10.1200/JCO.2001.19.11.2797, indexed in Pubmed: 11387350

72. Lecouvet FE, Talbot JN, Messiou C, et al. EORTC Imaging Group. Monitoring the response of bone metastases to treatment with Magnetic Resonance Imaging and nuclear medicine techniques: a review and position statement by the European Organisation for Research and Treatment of Cancer imaging group. Eur J Cancer. 2014; 50(15): 2519-2531, doi: 10.1016/j. ejca.2014.07.002, indexed in Pubmed: 25139492.

73. Padhani AR, Gogbashian A. Bony metastases: assessing response to therapy with whole-body diffusion MRI. Cancer Imaging. 2011; 11(1A): S129-S154, doi: 10.1102/1470-7330.2011.9034.

74. Lafourcade A, His M, Baglietto L, et al. Factors associated with breast cancer recurrences or mortality and dynamic prediction of death using history of cancer recurrences: the French E3N cohort. BMC Cancer. 2018; 18(1): 171, doi: 10.1186/s12885-018-4076-4, indexed in Pubmed: 29426294.

75. van Dongen JA, Voogd AC, Fentiman IS, et al. Long-term results of a randomized trial comparing breast-conserving therapy with mastectomy: European Organization for Research and Treatment of Cancer 10801 trial. J Natl Cancer Inst. 2000; 92(14): 1143-1150, doi: 10.1093/jnci/92.14.1143, indexed in Pubmed: 10904087

76. Grassetto G, Fornasiero A, Otello D, et al. 18F-FDG-PET/CT in patients with breast cancer and rising $\mathrm{Ca} 15-3$ with negative conventional imaging: a multicentre study. Eur J Radiol. 2011; 80(3): 828-833, doi: 10.1016/j. ejrad.2010.04.029, indexed in Pubmed: 20547020.

77. Grahek D, Montravers F, Kerrou K, et al. [18F]FDG in recurrent breast cancer: diagnostic performances, clinical impact and relevance of induced changes in management. Eur J Nucl Med Mol Imaging. 2004; 31(2): 179-188, doi: 10.1007/s00259-003-1348-1, indexed in Pubmed: 15129699.

78. Cochet A, David S, Moodie K, et al. The utility of 18 F-FDG PET/CT for suspected recurrent breast cancer: impact and prognostic stratification. Cancer Imaging. 2014; 14: 13, doi: 10.1186/1470-7330-14-13, indexed in Pubmed: 25608599 
79. Aukema TS, Rutgers EJ, Vogel WV, et al. The role of FDG PET/CT in patients with locoregional breast cancer recurrence: a comparison to conventional imaging techniques. Eur J Surg Oncol. 2010; 36(4): 387-392, doi: 10.1016/j. ejso.2009.11.009, indexed in Pubmed: 19962268.

80. Schmidt GP, Baur-Melnyk A, Haug A, et al. Comprehensive imaging of tumor recurrence in breast cancer patients using whole-body MRI at 1.5 and $3 \mathrm{~T}$ compared to FDG-PET-CT. Eur J Radiol. 2008; 65(1): 47-58, doi: 10.1016/j. ejrad.2007.10.021, indexed in Pubmed: 18082989.

81. Evangelista L, Baretta Z, Vinante L, et al. Tumour markers and FDG PET/CT for prediction of disease relapse in patients with breast cancer. Eur J Nucl Med Mol Imaging. 2011; 38(2): 293-301, doi: 10.1007/s00259-010-1626-7, indexed in Pubmed: 20882280.

82. Sawicki LM, Grueneisen J, Schaarschmidt BM, et al. Evaluation of ${ }^{1}$ F-FDG PET/MRI, ${ }^{1}$ F-FDG PET/CT, MRI, and CT in whole-body staging of recurrent breast cancer. Eur J Radiol. 2016; 85(2): 459-465, doi: 10.1016/j. ejrad.2015.12.010, indexed in Pubmed: 26781152.

83. Groheux D, Sanna A, Majdoub M, et al. Baseline Tumor 18F-FDG Uptake and Modifications After 2 Cycles of Neoadjuvant Chemotherapy Are Prognostic of Outcome in ER+/HER2- Breast Cancer. J Nucl Med. 2015; 56(6): 824-831, doi: 10.2967/jnumed.115.154138, indexed in Pubmed: 25883123.

84. Taghipour M, Wray R, Sheikhbahaei S, et al. FDG Avidity and Tumor Burden: Survival Outcomes for Patients With Recurrent Breast Cancer. AJR Am J Roentgenol. 2016; 206(4): 846-855, doi: 10.2214/AJR.15.15106, indexed in Pubmed: 27003053.

85. Chang CC, Chen CJ, Hsu WL, et al. Prognostic Significance of Metabolic Parameters and Textural Features on F-FDG PET/CT in Invasive Ductal Carcinoma of Breast. Sci Rep. 2019; 9(1): 10946, doi: 10.1038/s41598019-46813-5, indexed in Pubmed: 31358786.

86. Davies C, Godwin J, Gray R, et al. Early Breast Cancer Trialists' Collaborative Group (EBCTCG). Relevance of breast cancer hormone receptors and other factors to the efficacy of adjuvant tamoxifen: patient-level meta-analysis of randomised trials. Lancet. 2011; 378(9793): 771-784, doi: 10.1016/S01406736(11)60993-8, indexed in Pubmed: 21802721.

87. Linden HM, Stekhova SA, Link JM, et al. Quantitative fluoroestradiol positron emission tomography imaging predicts response to endocrine treatment in breast cancer. J Clin Oncol. 2006; 24(18): 2793-2799, doi: 10.1200/JCO.2005.04.3810, indexed in Pubmed: 16682724.

88. Nienhuis $\mathrm{HH}$, van Kruchten M, Elias SG, et al. F-Fluoroestradiol Tumor Uptake Is Heterogeneous and Influenced by Site of Metastasis in Breast Cancer Patients. J Nucl Med. 2018; 59(8): 1212-1218, doi: 10.2967/jnumed.117.198846, indexed in Pubmed: 29602822.
89. Slamon DJ, Clark GM, Wong SG, et al. Human breast cancer: correlation of relapse and survival with amplification of the HER-2/neu oncogene. Science. 1987; 235(4785): 177-182, doi: 10.1126/science.3798106, indexed in Pubmed: 3798106.

90. Dijkers EC, Oude Munnink TH, Kosterink JG, et al. Biodistribution of 89Zr-trastuzumab and PET imaging of HER2-positive lesions in patients with metastatic breast cancer. Clin Pharmacol Ther. 2010; 87(5): 586-592, doi: 10.1038/clpt.2010.12, indexed in Pubmed: 20357763.

91. Smyczek-Gargya B, Fersis N, Dittmann H, et al. PET with [18F]fluorothymidine for imaging of primary breast cancer: a pilot study. Eur J Nucl Med Mol Imaging. 2004; 31(5): 720-724, doi: 10.1007/s00259-004-1462-8, indexed in Pubmed: 14991243

92. Contractor KB, Kenny LM, Stebbing J, et al. [18F]-3'Deoxy-3'-fluorothymidine positron emission tomography and breast cancer response to docetaxel. Clin Cancer Res. 2011; 17(24): 7664-7672, doi: 10.1158/1078-0432.CCR11-0783, indexed in Pubmed: 22028493

93. Yoon HJ, Kang KW, Chun InK, et al. Correlation of breast cancer subtypes, based on estrogen receptor, progesterone receptor, and HER2, with functional imaging parameters from Ga-RGD PET/CT and ${ }^{1}$ F-FDG PET/CT. Eur J Nucl Med Mol Imaging. 2014; 41(8): 1534-1543, doi: 10.1007/s00259014-2744-4, indexed in Pubmed: 24652232.

94. Beer AJ, Niemeyer M, Carlsen J, et al. Patterns of alphavbeta3 expression in primary and metastatic human breast cancer as shown by 18F-Galacto-RGD PET. J Nucl Med. 2008; 49(2): 255-259, doi: 10.2967/jnumed.107.045526, indexed in Pubmed: 18199623.

95. Cheng J, Lei Li, XU J, et al. 18F-fluoromisonidazole PET/CT: a potential too for predicting primary endocrine therapy resistance in breast cancer. J Nucl Med. 2013; 54(3): 333-340, doi: 10.2967/jnumed.112.111963, indexed in Pubmed: 23401605

96. Tolkach Y, Gevensleben H, Bundschuh R, et al. Prostate-specific membrane antigen in breast cancer: a comprehensive evaluation of expression and a case report of radionuclide therapy. Breast Cancer Res Treat. 2018; 169(3): 447-455, doi: 10.1007/s10549-018-4717-y, indexed in Pubmed: 29455299

97. Kumar R, Mittal BR, Bhattacharya A, et al. Synchronous Detection of Male Breast Cancer and Prostatic Cancer in a Patient With Suspected Prostatic Carcinoma on 68Ga-PSMA PET/CT Imaging. Clin Nucl Med. 2018; 43(6): $431-$ 432, doi: 10.1097/RLU.0000000000002063, indexed in Pubmed: 29538032.

98. Sathekge M, Lengana T, Modiselle M, et al. Ga-PSMA-HBED-CC PET imaging in breast carcinoma patients. Eur J Nucl Med Mol Imaging. 2017; 44(4): 689-694, doi: 10.1007/s00259-016-3563-6, indexed in Pubmed: 27822700. 